Int. J. Electrochem. Sci., 12 (2017) $9829-9843$

International Journal of

ELECTROCHEMICAL

SCIENCE

www.electrochemsci.org

\title{
A Composite Anodic Coating Containing Graphene on AZ31 Magnesium Alloy
}

\author{
Baojun Han ${ }^{1,2, *}$, Yang Yang ${ }^{1,2}$, Zhijuan Huang ${ }^{1,2}$, Li You $^{2}$, Huan Huang ${ }^{2}$, Kejun Wang ${ }^{2}$ \\ ${ }^{1}$ Jiangxi Provincial Engineering Research Center for Magnesium alloys, Gannan Normal University, \\ Ganzhou 341000, P. R. China \\ ${ }^{2}$ Schoolof Chemistry and Chemical Engineering, Gannan Normal University, Ganzhou 341000, P.R. \\ China \\ *E-mail: baojunhan@126.com
}

doi: $10.20964 / 2017.10 .30$

Received: 14 June 2017 / Accepted: 31 July 2017 / Published: 12 September 2017

Graphene was added to the electrolyte during the preparation of an anodic oxidation coating on an AZ31 magnesium alloy, and the effects of graphene on the surface morphology, chemical composition and phase composition of the coatings were investigated by scanning electron microscopy (SEM), energy dispersive spectroscopy (EDS), X-ray diffraction (XRD) and X-ray photoelectron spectroscopy (XPS). The corrosion resistance of the coatings was evaluated via electrochemical measurements, including dynamic polarization curves and electrochemical impendence spectroscopy (EIS). The results indicated that graphene was successfully incorporated into the anodic oxidation coating, and the number of micro-pores and cracks on the coating dramatically decreased. Moreover, the electrochemical measurements demonstrated that the corrosion resistance of the coating improved because the corrosion potential increased $470 \mathrm{mV}$ and the corrosion current density decreased approximately three orders of magnitude when $0.5 \mathrm{~g} \mathrm{~L}^{-1}$ of graphene was added to the electrolyte.

Keywords: AZ31 magnesium alloy; anodic oxidation coating; graphene; corrosion resistance

\section{$\underline{\text { FULL TEXT }}$}

(C) 2017 The Authors. Published by ESG (www.electrochemsci.org). This article is an open access article distributed under the terms and conditions of the Creative Commons Attribution license (http://creativecommons.org/licenses/by/4.0/). 